\title{
Volume de calda e concentração de retardantes do fogo em queimas controladas em área de eucalipto na transição Cerrado-Amazônia
}

\author{
Volume of the syrup and the concentration of fire retardants in prescribed \\ burnings in an eucalyptus area in the Cerrado-Amazon transition
}

\author{
Daiane Cristina de Lima ${ }^{\mathrm{I}}$, Adilson Pacheco de Souza ${ }^{\mathrm{II}}$, \\ Fernando Gonçalves Cabeceira ${ }^{\text {III }}$, Josiane Fernandes Keffer ${ }^{\mathrm{I}}$, \\ Mariana Pizzatto $^{\mathrm{IV}}$, Daniela Roberta Borella ${ }^{\mathrm{v}}$
}

\begin{abstract}
Resumo
Os aceiros químicos consistem em faixas com aplicações de retardantes do fogo utilizados no combate indireto de incêndios florestais. Embora eficiente, a inexistência de recomendações de uso prático restringe a aplicação e eficácia dos produtos. Objetivou-se avaliar a eficiência de retardantes do fogo em queimas controladas em área de Eucalyptus urograndis (Eucalyptus grandis x Eucalyptus urophylla) (clone H13) com 6,0 anos de idade, por meio da aplicação de diferentes concentrações e volumes de calda, considerando $1,0 \mathrm{~h}$ como tempo pós-aplicação. Foram avaliados três retardantes do fogo: dois comerciais (Phos-Chek WD881 ${ }^{\circledR}$ e Hold Fire ${ }^{\circledR}$ ) e um alternativo (polímero hidrorretentor: Nutrigel ${ }^{\circledR}$ ) com cinco concentrações e nos volumes de calda de 0,5; 1,0 e 2,0 L m m $^{-2}$ (apenas água e sem aplicação de calda foram as referências). O comportamento do fogo foi avaliado pela velocidade de propagação do fogo, comprimento das chamas (e suas respectivas taxas de reduções) e material combustível remanescente e consumido. Para todos os retardantes, o aumento do volume de calda propiciou redução das variáveis do comportamento do fogo, sendo recomendado a aplicação de calda equivalente a $2,0 \mathrm{~L} \mathrm{~m}^{-2}$. As eficiências do Phos-Chek WD881® e do Hold Fire ${ }^{\circledR}$ apresentaram comportamentos lineares crescentes indicando que o aumento da concentração propiciou maior do controle do fogo, todavia, o Nutrigel ${ }^{\circledR}$ apresentou eficiência com resposta quadrática ao incremento das concentrações. A concentração ideal variou de acordo com o produto, sendo recomendado $1,0 \mathrm{~mL} \mathrm{~L}^{-1} ; 1,5 \mathrm{~mL} \mathrm{~L}^{-1} ; 0,0060 \mathrm{~g} \mathrm{~L}^{-1}$ para Phos-Chek WD881 ${ }^{\circledR}$, Hold Fire $^{\circledR}$ e Nutrigel $^{\circledR}$, respectivamente.
\end{abstract}

Palavras-chave: Incêndios florestais; Aceiros químicos; Combate indireto do fogo; Polímero hidroretentor

\footnotetext{
Engenheira Florestal, MSc., Programa de Pós-Graduação em Ciências Ambientais, Universidade Federal de Mato Grosso, Instituto de Ciências Naturais, Humanas e Sociais, Av. Alexandre Ferronatto 1200, Distrito Industrial, CEP 78550-726, Sinop (MT), Brasil. daiac.lima1@gmail.com (ORCID: 0000-0001-8027-4500) / kefferjf@gmail.com (ORCID: 0000-0001-6134-7372)

II Engenheiro Agrícola, Professor Adjunto, Universidade Federal de Mato Grosso, Instituto de Ciências Agrárias e Ambientais, Av. Alexandre Ferronatto 1200, Distrito Industrial, CEP 78550-726, Sinop (MT), Brasil. pachecoufmt@gmail.com (ORCID: 0000-0003-4076-1093)

III Biológo, MSc. Programa de Pós-Graduação em Ecologia e Conservação da Biodiversidade, Universidade Federal de Mato Grosso, Instituto de Biociências, Av. Fernando Corrêa da Costa 2367, Boa Esperança, CEP 78060-900, Cuiabá (MT), Brasil. fernando.cabeceira@gmail.com (ORCID: 0000-0001-5128-4187)

Iv Tecnológa em Horticultura, MSc., Doutoranda, Programa de Pós-Graduação em Agricultura Tropical, Universidade Federal de Mato Grosso, Faculdade de Agronomia e Zootecnia, Av. Fernando Corrêa da Costa 2367, Boa Esperança, CEP 78060-900, Cuiabá (MT), Brasil. marianapizzatto23@ gmail.com (ORCID: 0000-0001-5751-0368)

v Engenheira Florestal, MSc., Doutoranda, Programa de Pós-Graduação em Física Ambiental, Universidade Federal de Mato Grosso, Instituto de Física, Av. Fernando Corrêa da Costa 2367, Boa Esperança, CEP 78060-900, Cuiabá (MT), Brasil. drborella@gmail.com (ORCID: 0000-0003-29412116)
} 


\begin{abstract}
The chemical firebreaks consist of bands with applications of fire retardants and are used in the indirect combat of forest fires. Despite its efficiency, the lack of practical use recommendations restricts the application and effectiveness of the products. This paper evaluated the efficiency of fire retardants in controlled burning in area of 6.0 years old of the Eucalyptus urograndis (Eucalyptus grandis x Eucalyptus urophylla) (clone H13) by applying different concentrations of product and volumes of the syrup, after 1.0h of retardants application. Two commercially fire retardants (Phos-Chek WD881 ${ }^{\circledR}$ and Hold Fire ${ }^{\circledR}$ ) and an alternative (hydro retainer polymer - Nutrigel ${ }^{\circledR}$ ) were tested with five concentrations each and volumes of the syrup of $0.5 ; 1.0$ and $2.0 \mathrm{~L} \mathrm{~m}^{-2}$ (only water and without application syrup were the references). The fire behavior was evaluated through fire propagation speed, flame length (and their respective reduction rates) and the fuel material remaining and consumed. For all the retardants, the increase of volumes of the syrup promoted reduction of fire behavior variables, being recommended an application of syrup equivalent to $2.0 \mathrm{~L} \mathrm{~m}^{-2}$. The efficiencies of the Phos-Chek WD881 ${ }^{\circledR}$ and of Hold Fire ${ }^{\circledR}$ presented increasing linear models with increased concentration improved retarder efficacy, however, the Nutrigel ${ }^{\circledR}$ presented efficiency with quadratic response to increased concentrations. The ideal concentration varied according to the product, recommended $1.0 \mathrm{~mL} \mathrm{~L}^{-1} ; 1.5 \mathrm{~mL} \mathrm{~L}^{-1} ; 0.0060 \mathrm{~g} \mathrm{~L}^{-1}$ for Phos-Chek ${ }^{\circledR}$, Hold Fire ${ }^{\circledR}$ and Nutrigel ${ }^{\circledR}$, respectively.
\end{abstract}

Keywords: Forest fires; Chemical firing; Indirect fire fighting; Hydro retainer polymer

\title{
Introdução
}

O combate aos incêndios florestais por gestores ambientais consiste no planejamento de técnicas eficientes fundamentadas no comportamento do fogo intrínseco do ambiente de ocorrência. Em geral, as variáveis descritivas do comportamento do fogo são a velocidade de propagação do fogo e o comprimento das chamas, que podem ser monitoradas in loco e/ou modeladas pela interação entre o material combustível (serapilheira), topografia e elementos meteorológicos (SOARES; BATISTA, 2007; NORTH et al., 2015).

Dentre as técnicas indiretas de combate a incêndios florestais, uma alternativa eficaz é a construção de aceiros químicos, que consiste na criação de faixas úmidas com associação da água e retardantes do fogo. Os aceiros químicos promovem o aumento da umidade dos materiais combustíveis com a finalidade de reduzir a sua flamabilidade (CANZIAN et al., 2016; PLUCINSKI; SULLIVAN; HURLEY, 2017), que por sua vez minimiza a severidade da linha do fogo (intensidade) para a entrada dos brigadistas no combate direto as chamas (MCCARTHY; PLUCINSKI; GOULD, 2012).

Os retardantes do fogo são produtos aplicados em soluções aquosas, que retardam a capacidade de evaporação da umidade do material combustível por meio do impedimento dos gases responsáveis pelo seu pré-aquecimento (GIMÉNEZ et al., 2004; RIBEIRO et al., 2006; PLUCINSKI; SULLIVAN; HURLEY, 2017). Esses produtos podem ser categorizados em: i) longa duração: inibem as reações químicas do material combustível, tornando-o não inflamável, são constituídos de sais de amoníaco e geralmente deixam resíduos após a evaporação da água; ii) curta duração (LGE): dificultam a evaporação da água do material combustível por serem espumógenos e viscosantes (barreira física), e geralmente, não deixam resíduos e são utilizados no combate indireto a incêndios florestais (BATISTA et al., 2008).

A utilização de retardantes do fogo permite boas respostas no combate a incêndios florestais, entretanto, ainda existem lacunas que envolvem possíveis contaminações ambientais (DIETRICH et al., 2014), preços elevados (MACHADO FILHO et al., 2012) e falta de informações de preparação em relação a volumes de calda e concentrações dos produtos para uso em diferentes tipos de materiais combustíveis (RIBEIRO et al., 2006; MACHADO FILHO et al., 2012; FIEDLER et al., 2015; PLUCINSKI; SULLIVAN; HURLEY, 2017; IBAMA, 2018). Aliado aos problemas supracitados, a eficiência dos retardantes é dependente da disponibilidade de água para captação e diluição nas áreas de ocorrência de incêndios (GIMÉNEZ et al., 2004; RIBEIRO et al., 2006; CANZIAN et al., 2018). 
Dessa forma, ainda são necessários estudos voltados às recomendações ideais de usos práticos dos retardantes disponíveis no mercado brasileiro, visto que, não existe uma legislação específica pertinente ao seu uso no país. Essas análises devem envolver, sobretudo, o efeito das concentrações em diferentes volumes de calda de água visando à máxima eficiência dos produtos, redução de custos e desperdícios com aplicações excessivas.

Em substituição aos retardantes comerciais, o emprego de polímeros hidroretentores popularmente conhecidos como "hidrogéis", utilizados nos setores agrícolas e florestais como condicionadores hídricos do solo, pode ser uma alternativa eficaz no combate indireto dos incêndios florestais, uma vez que, podem conservar a umidade dos materiais combustíveis por um período prolongado sem resíduos contaminantes (NAVROSKI et al., 2015). Os polímeros hidroretentores são aglomerados de moléculas orgânicas de metilcelulose, que ao serem hidratadas, aumentam o tamanho e formato, liberando a umidade interna por difusão ao ambiente (BALENA, 1998; GUILHERME et al., 2015), nesse caso específico, liberando a umidade ao material combustível.

Neste contexto, objetivou-se avaliar a eficiência de retardantes do fogo de curta duração, em diferentes concentrações e volumes de calda, na redução do comportamento do fogo em queimas controladas em área de cultivo do híbrido Eucalyptus urograndis (Eucalyptus grandis x Eucalyptus urophylla clone H13), com 6,0 anos de idade, na transição Cerrado-Amazônia do estado de Mato Grosso. Destaca-se que não se buscou a comparação entre produtos, visto que os princípios ativos e classificações comerciais são distintas, e além disso, optou-se pela avaliação de um produto alternativo como retardante (polímero hidrorretentor).

\section{Material e método}

\section{Caracterização do local de estudo}

O estudo foi realizado nos meses de julho e agosto de 2017, na Fazenda Santo Antônio (UPL3) da Companhia Brasil Foods S.A. (BRF), no município de Sorriso, unidade de Lucas do Rio Verde $\left(12^{\circ} 51^{\prime} 35,04\right.$ ” S e $55^{\circ} 52^{\prime} 33,54^{\prime \prime}$ W, com relevo plano e altitude de $\left.365 \mathrm{~m}\right)$, estado de Mato Grosso, Brasil. A área experimental localiza-se na mesorregião do Estado considerada como transição dos biomas Cerrado e Amazônia. Segundo a classificação de Köppen, a região apresenta clima do tipo tropical quente e úmido $(\mathrm{Aw})$, com duas estações hídricas predominantes: seca (maio a setembro) e chuvosa (outubro a abril), com precipitação média anual de $1.900 \mathrm{~mm}$ e temperatura média mensal do ar variando entre 22,0 a $25,0^{\circ} \mathrm{C}$ (SOUZA et al., 2013).

O experimento foi conduzido no centro de um talhão com cultivo do híbrido Eucalyptus urograndis (Eucalyptus grandis x Eucalyptus urophylla clone H13), com 6,0 anos de idade, cujas árvores foram implantadas no espaçamento de $3,0 \times 3,0 \mathrm{~m}$ (linha x entrelinha), submetidas à desrama e apresentavam altura total média de $26,0 \mathrm{~m}$ e percentual de ocupação de copa de $62,0 \%$. O talhão apresentava a leste a bordadura com um fragmento de mata ciliar e a oeste com área de lavoura com plantios sucessivos de soja, milho e algodão (ALVES et al., 2017).

\section{Instalação das parcelas e queimas controladas}

Foram instaladas parcelas de 25,0 x 3,0 m, compostas de subparcelas de 3,0 x 3,0 m (comprimento x largura), intercaladas "sem" e "com" aplicação de retardantes do fogo. As subparcelas foram divididas em três repetições de 1,0 x 3,0 m (comprimento x largura), nas quais foram fixados pontos de observações das variáveis do comportamento do fogo. As interfaces das parcelas foram delimitadas por aceiros com 1,0 m de largura para evitar a passagem do fogo para áreas circunvizinhas (ALVES et al., 2017). Entre as subparcelas foram instaladas zonas de transições de 1,0 × 3,0 m (comprimento x largura) para a eliminação de possíveis resíduos 
de calda com retardantes (respingos) das áreas que receberam para aquelas sem aplicação de retardantes do fogo.

Avaliou-se a eficiência de três retardantes do fogo de curta duração associados com água, sendo dois comerciais (Phos-Chek WD881 ${ }^{\circledR}$ e Hold Fire ${ }^{\circledR}$ ) e um alternativo (polímero hidrorretentor - Nutrigel ${ }^{\circledR}$ ), além das referências (somente água e sem aplicação de calda). As classificações e composições dos seus fabricantes para os produtos comerciais são: i) PhosChek WD881 ${ }^{\circledR}$, retardante classe A (materiais sólidos) espumoso, curta duração, constituído da solução de sulfonato de $\alpha$-olefina, 2,4-pentanodiol, 2-metil, água, álcool laurílico e $d$-limoneno; nesse caso foram aplicadas as concentrações de 0 (água); 0,1; 0,3; 0,6;0,8 e 1,0 mL L-1; ii) Hold Fire $^{\circledR}$, retardante classe A oleaginoso, curta duração, constituído de óleos orgânicos, polímeros higroscópicos e surfactantes, sendo aplicado nas concentrações de 0 (água); 0,7; 0,9; 1,1; 1,3 e 1,5 $\mathrm{mL} \mathrm{L}{ }^{-1}$.

O polímero hidrorretentor não possui recomendação para uso como retardante de fogo e é comercialmente conhecido como "hidrogel", com recomendação técnica para uso na implantação de áreas agrícolas ou florestais, visto que o mesmo se configura como moléculas orgânicas. Nesse caso, o produto usado foi o Nutrigel ${ }^{\circledR}$, que apresenta 27,$80 ; 49,70 ; 8,70$ e 18,10\% de $\mathrm{CaO}, \mathrm{CaCO}_{3}, \mathrm{MgO}$ e $\mathrm{MgCO}_{3}$, com poder de neutralização de 67,50\% (classificação semelhante ao calcário dolomítico) e polímeros. Após avaliação do entupimento de bicos de pulverizadores costais e motorizados foram definidas as concentrações para avaliação do produto de 0,0010 ; 0,$0025 ; 0,0050 ; 0,0075$ e $0,0100 \mathrm{~g} \mathrm{~L}^{-1}$, correspondentes às variações entre 0,1 e 1,0 grama de polímero por litro de água (recomendações agroflorestais).

As concentrações dos retardantes do fogo consideradas foram aplicadas nos volumes de calda de 0,$5 ; 1,0$ e $2,0 \mathrm{~L} \mathrm{~m}^{-2}$ (variação de 50 e $100 \%$ da calda), por meio de pulverizações sobre o material combustível das subparcelas com uma bomba costal anti-incêndio, dispondo de um bico de abertura tipo leque para aumentar a uniformidade de aplicação. As queimas controladas ocorreram após $1 \mathrm{~h}$ de aplicação dos retardantes nas subparcelas.

Antes das queimas controladas, realizou-se a caracterização do material combustível disponível por meio de coletas aleatórias de amostras destrutivas de $1,0 \mathrm{~m}^{2} \mathrm{em}$ áreas distantes em no máximo 3,0 $\mathrm{m}$ das subparcelas, na mesma linha de plantio. Nessas amostras, foram obtidas a espessura média da camada de material combustível, e separação das partições vegetais nas classes: i) material combustível morto (seco): folha, casca, galhos com diâmetro (d) $<0,7 \mathrm{~cm}(\mathrm{G} 1)$, e galhos com $0,7 \leq \mathrm{d} \leq 2,5 \mathrm{~cm}(\mathrm{G} 2)$; ii) material combustível vivo (úmido): plantas herbáceas e gramíneas (MH) (ALVES et al., 2017). As partições vegetais foram pesadas em campo para obtenção da massa fresca, com posterior secagem em estufa de circulação forçada de ar a temperatura de $65,0^{\circ} \mathrm{C}\left( \pm 2,0^{\circ} \mathrm{C}\right)$ até atingir massa constante, para a determinação da massa seca e o teor de umidade. A densidade do material combustível por hectare foi obtida pela soma das partições vegetais das amostras (ALVES et al., 2017).

As variáveis meteorológicas (temperatura do ar, umidade relativa do ar, velocidade e direção do vento) foram monitoradas a cada minuto durante as queimas controladas com uma estação meteorológica automática portátil conectada a um datallogger (Instrutemp Weather Station - modelo WH1080), instalada a 2,0 m de altura, no centro do talhão.

As queimas controladas ocorreram a favor do vento entre as $10 \mathrm{~h}$ e $14 \mathrm{~h}$ (horário solar local), definidos previamente como os horários de maior espalhamento do fogo e com poucas variações dos elementos meteorológicos (ALVES et al., 2017). O comportamento do fogo foi avaliado in-loco (medidas diretas) por meio das variáveis: i) velocidade de propagação do fogo (VP, em $\mathrm{m} \mathrm{min}^{-1}$ ), cronometrando o tempo de percurso da linha de fogo entre dois pontos de observações consecutivos; e ii) comprimento das chamas $(\mathrm{L}$, em $\mathrm{cm})$, por meio da estimativa visual com uma régua fixada junto ao ponto de observação no momento da passagem do fogo. Posteriormente, obtiveram-se as taxas de redução da velocidade de propagação do fogo (TRVP) e do comprimento das chamas (TRL), considerando como referência as subparcelas que não receberam produtos ou água. 
O material combustível remanescente pós-queima foi coletado com amostras aleatórias de $1,0 \mathrm{~m}^{2}$ nas subparcelas queimadas. Posteriormente, foram submetidas à secagem em estufa de circulação forçada de ar a temperatura de $65,0^{\circ} \mathrm{C}\left( \pm 2,0^{\circ} \mathrm{C}\right)$ até atingir a massa constante, para a determinação da massa seca total do material combustível remanescente e consumido na queima (com base no combustível disponível antes da queima).

\section{Delineamento estatístico}

O delineamento experimental adotado foi de parcelas subdividas, em blocos casualizados, com um arranjo fatorial em 2 níveis: 6 x 3 (concentrações do retardante x volumes de calda), com três repetições por tratamento, para cada retardante avaliado. Os dados foram submetidos à análise de normalidade dos resíduos pelo teste de Shapiro-Wilk $(\mathrm{p} \leq 0,05)$. Posteriormente, realizou-se a análise de variância (ANOVA) para as variáveis do material combustível e do fatorial (concentrações $\mathrm{x}$ volumes de calda do retardante) para cada produto, e quando observadas diferenças significativas entre as médias, aplicou-se o teste de Scott-Knott a 5,0\% de significância. A determinação da concentração ideal dos retardantes (com base nas concentrações pré-determinadas) para cada volume de calda foi obtida por meio de regressões (lineares e/ou polinomiais quadráticas), entre as variáveis do comportamento do fogo (variável dependente) e concentrações de cada produto (variável independente).

\section{Resultados e discussão}

\section{Caracterização do material combustível disponível}

O material combustível disponível apresentava-se homogêneo nas subparcelas que receberam as combinações de concentrações e volumes de calda dos retardantes do fogo, sendo essa característica fundamental para a avaliação da eficiência dos retardantes, sem interferências de fatores ambientais externos. Por conseguinte, não foram observadas diferenças significativas entre as classes do material combustível quanto à espessura da camada, massa seca (parcial e total) e teor de umidade (Tabela 1).

$\mathrm{Na}$ distribuição da massa seca das classes do material combustível encontrou-se maior volume de folhas $(11,18 ; 11,10$ e 11,25 t ha-1), seguido de galhos médios (classe G2) $(8,42 ; 8,05$ e 8,69 $\left.\mathrm{t} \mathrm{ha}^{-1}\right)$, galhos finos (classe G1) $\left(4,78 ; 4,36\right.$ e 4,53 t ha-1), cascas $\left(2,39 ; 2,05\right.$ e 2,30 t ha $\left.{ }^{-1}\right)$ e material herbáceo (classe $\mathrm{MH})\left(0,60 ; 0,92\right.$ e $\left.0,91 \mathrm{t} \mathrm{ha}^{-1}\right)$, nas áreas que receberam os retardantes Phos-Chek WD881 ${ }^{\circledR}$, Hold Fire ${ }^{\circledR}$ e Nutrigel ${ }^{\circledR}$, respectivamente. A distribuição dessas classes pode ser considerada como similar a outros estudos voltados para caracterização de serapilheira (material combustível) em áreas de eucalipto na transição Cerrado-Amazônia (BARLOW et al., 2007; VIERA et al., 2014; CARMO et al., 2018). O maior volume de folhas, reforça os perigos de incêndios florestais na área em estudo, uma vez que esse material combustível apresenta menor timelag, tempo necessário para a completa evaporação da água contida no material combustível (ROTHERMEL, 1972).

A relação da massa seca total média nas parcelas foi de $27,14 \mathrm{t} \mathrm{ha}^{-1}$ para as áreas que receberam o retardante Phos-Chek WD881 ${ }^{\circledR} ; 25,97$ t ha $^{-1}$ com Hold Fire ${ }^{\circledR}$ e 27,35 t ha ${ }^{-1}$ com Nutrigel $^{\circledR}$, respectivamente. Alves et al. (2017) observaram para a mesma área de Eucalyptus urograndis com idade de 4,5 anos, observaram massas secas totais de 14,3 $\mathrm{t} \mathrm{ha}^{-1}$; todavia, Carmo et al. (2018) avaliando esse mesmo híbrido com 7,0 anos na região Médio-Norte de Mato Grosso, obtiveram massas secas totais de $31,0 \mathrm{t} \mathrm{ha}^{-1}$, no período seco da região. Em áreas de Eucalyptus urograndis com idade entre 5,0 a 7,0 anos, é esperado o aumento da deposição de resíduos vegetais, consequentemente na massa seca total do material combustível (SCHUMACHER; 
WITSCHORECK; CALIL, 2011; CARMO et al., 2018). Entretanto, em povoamentos de eucalipto com idades superiores a 7,0 anos, na ausência de tratos silviculturais como o desbaste, pode ocorrer diminuição no número de árvores devido à competição por recursos naturais, que incide sobre a redução da carga de combustível depositado (CAO et al., 2010; CARMO et al., 2018).

Para o teor de umidade do material combustível, os valores foram considerados baixos para as classes folhas, G1, G2 e cascas, com umidades inferiores a 20,77; 17,22 e 14,60\% nas parcelas de Phos-Chek WD881 ${ }^{\circledR}$, Hold Fire ${ }^{\circledR}$ e Nutrigel $^{\circledR}$, respectivamente. Entretanto, Alves et al. (2017) para a mesma área de Eucalyptus urograndis com 4,5 anos obtiveram teores de umidade do material combustível inferiores a $9,0 \%$ no mês de agosto. Os maiores teores de umidade observados em relação aos de Alves et al. (2017), podem ser resultantes do aumento da deposição do combustível na área de Eucalyptus urograndis, que afeta as taxas de evaporações da água disponível no solo (SLIJEPCEVIC et al., 2018). Nesse caso, o aumento da camada de material combustível permitiu maior manutenção da umidade nos espaços porosos nas partições vegetais em função das reduções das trocas gasosas (KREYE; KOBZIAR; ZIPPERER, 2013).

Tabela 1 - Características do material combustível disponível nas parcelas de queima controlada em área de Eucalyptus urograndis (clone H13), no município de Sorriso - MT, Brasil

Table 1 - Fuel material available in the controlled burning plots Eucalyptus urograndis (clone H13) area, in the municipality of Sorriso - MT state, Brazil

\begin{tabular}{|c|c|c|c|c|c|c|c|}
\hline \multirow{2}{*}{ Retardante } & \multirow{2}{*}{ Classes } & \multicolumn{6}{|c|}{ Concentração do retardante } \\
\hline & & $\mathrm{C}_{1}$ & $\mathrm{C}_{2}$ & $\mathrm{C}_{3}$ & $\mathrm{C}_{4}$ & $\mathrm{C}_{5}$ & $\mathrm{C}_{6}$ \\
\hline & & \multicolumn{6}{|c|}{ Espessura da camada $(\mathrm{cm})$} \\
\hline Phos-Chek WD881 ${ }^{\circledR}$ & - & 8,67 & 13,00 & 9,10 & 10,20 & 7,00 & 8,00 \\
\hline Hold Fire ${ }^{\circledR}$ & - & 8,67 & 10,00 & 7,33 & 8,66 & 9,00 & 10,33 \\
\hline \multirow[t]{2}{*}{ Nutrigel $^{\circledR}$} & - & 8,67 & 8,83 & 9,00 & 11,33 & 9,00 & 9,67 \\
\hline & & \multicolumn{6}{|c|}{ Massa seca $\left(\mathrm{t} \mathrm{ha}^{-1}\right)$} \\
\hline \multirow{6}{*}{ Phos-Chek WD881 ${ }^{\circledR}$} & Folha & 11,30 & 11,10 & 11,90 & 11,80 & 9,80 & 11,30 \\
\hline & Casca & 2,93 & 1,10 & 3,10 & 2,20 & 2,40 & 2,60 \\
\hline & G1 & 4,17 & 4,80 & 4,50 & 6,70 & 3,70 & 4,80 \\
\hline & $\mathrm{G} 2$ & 7,94 & 8,40 & 9,60 & 6,70 & 9,10 & 8,80 \\
\hline & $\mathrm{MH}$ & 0,43 & 0,90 & - & - & 0,90 & 0,20 \\
\hline & MS total & 26,76 & 26,45 & 29,09 & 27,04 & 25,87 & 27,65 \\
\hline \multirow{6}{*}{ Hold Fire $^{\circledR}$} & Folha & 11,27 & 12,02 & 10,46 & 11,70 & 11,38 & 9,80 \\
\hline & Casca & 2,93 & 1,61 & 1,64 & 1,94 & 2,55 & 1,62 \\
\hline & G1 & 4,17 & 4,64 & 4,12 & 4,86 & 4,20 & 4,20 \\
\hline & G2 & 7,94 & 8,54 & 4,38 & 8,34 & 8,74 & 10,40 \\
\hline & $\mathrm{MH}$ & 0,43 & - & - & - & 1,17 & 1,17 \\
\hline & MS total & 26,76 & 26,06 & 20,59 & 26,85 & 28,36 & 27,20 \\
\hline
\end{tabular}


Tabela 1 - Conclusão ...

Table 1 - Conclusion ...

\begin{tabular}{|c|c|c|c|c|c|c|c|}
\hline \multirow{2}{*}{ Retardante } & \multirow{2}{*}{ Classes } & \multicolumn{6}{|c|}{ Concentração do retardante } \\
\hline & & $\mathrm{C}_{1}$ & $\mathrm{C}_{2}$ & $\mathrm{C}_{3}$ & $\mathrm{C}_{4}$ & $\mathrm{C}_{5}$ & $\mathrm{C}_{6}$ \\
\hline & & \multicolumn{6}{|c|}{ Massa seca $\left(\mathrm{t} \mathrm{ha}^{-1}\right)$} \\
\hline \multirow{7}{*}{ Nutrigel ${ }^{\circledR}$} & Folha & 11,30 & 11,23 & 11,87 & 10,40 & 12,06 & 10,67 \\
\hline & Casca & 2,93 & 2,50 & 1,80 & 2,20 & 2,17 & 2,20 \\
\hline & G1 & 4,17 & 5,73 & 4,57 & 3,97 & 5,20 & 3,57 \\
\hline & G2 & 7,94 & 7,17 & 7,07 & 12,47 & 9,27 & 8,27 \\
\hline & MH & 0,43 & - & - & 1,10 & 0,83 & 1,27 \\
\hline & MS total & 26,76 & 26,63 & 25,27 & 30,10 & 29,53 & 25,80 \\
\hline & \multicolumn{7}{|c|}{ Teor de umidade (\%) } \\
\hline \multirow{5}{*}{ Phos-Chek WD881 ${ }^{\circledR}$} & Folha & 11,70 & 11,75 & 14,03 & 13,51 & 20,77 & 9,66 \\
\hline & Casca & 11,50 & 9,55 & 11,31 & 15,46 & 11,64 & 9,65 \\
\hline & G1 & 11,20 & 9,07 & 11,15 & 12,95 & 10,31 & 10,16 \\
\hline & G2 & 10,33 & 17,89 & 11,46 & 12,31 & 10,96 & 8,78 \\
\hline & MH & 21,23 & 36,79 & - & - & 58,97 & 38,18 \\
\hline \multirow{5}{*}{ Hold Fire $^{\circledR}$} & Folha & 11,70 & 17,22 & 10,91 & 14,15 & 11,58 & 11,54 \\
\hline & Casca & 11,50 & 8,20 & 9,87 & 15,00 & 10,27 & 10,70 \\
\hline & G1 & 11,20 & 9,35 & 8,54 & 12,67 & 11,13 & 11,88 \\
\hline & G2 & 10,33 & 8,95 & 9,97 & 12,08 & 9,42 & 9,77 \\
\hline & $\mathrm{MH}$ & 21,23 & - & - & - & 41,27 & 64,26 \\
\hline \multirow{5}{*}{ Nutrigel $^{\circledR}$} & Folha & 11,70 & 11,95 & 11,89 & 11,74 & 14,60 & 11,95 \\
\hline & Casca & 11,50 & 12,82 & 12,05 & 12,48 & 13,05 & 12,82 \\
\hline & G1 & 11,20 & 11,12 & 10,21 & 10,43 & 12,20 & 10,56 \\
\hline & G2 & 10,33 & 10,88 & 10,85 & 10,75 & 12,68 & 9,42 \\
\hline & $\mathrm{MH}$ & 21,23 & - & - & 25,31 & 43,08 & 20,68 \\
\hline
\end{tabular}

Fonte: Autores (2019)

Em que: Os valores médios dos tratamentos não apresentaram diferenças pelo teste de ScottKnott a 5,0\% de significância. Em que: G1: galho fino com diâmetro (d) $<0,7$ cm; G2: galho médio com diâmetro $0,7 \leq \mathrm{d} \leq 2,5 \mathrm{~cm} ; \mathrm{MH}$ : material herbáceo; -: $\mathrm{MH}$ ausente no tratamento; MS total: massa seca total; Concentração dos retardantes: Phos-Chek WD881 ${ }^{\otimes}\left(\mathrm{C}_{1}-0,0 ; \mathrm{C}_{2}-0,1 ; \mathrm{C}_{3}-0,3 ; \mathrm{C}_{4}{ }^{-}\right.$ 0,$6 ; \mathrm{C}_{5}-0,8$ e $\left.\mathrm{C}_{6}-1,0 \mathrm{~mL} \mathrm{~L}{ }^{-1}\right)$, Hold Fire ${ }^{\circledR}\left(\mathrm{C}_{1}-0,0 ; \mathrm{C}_{2}-0,7 ; \mathrm{C}_{3}-0,9 ; \mathrm{C}_{4}-1,1 ; \mathrm{C}_{5}-1,3\right.$ e $\left.\mathrm{C}_{6}-1,5 \mathrm{~mL} \mathrm{~L}^{-1}\right)$ e Nutrigel ${ }^{\circledR}\left(\mathrm{C}_{1}-0,0 ; \mathrm{C}_{2}-0,0010 ; \mathrm{C}_{3}-0,0025 ; \mathrm{C}_{4}-0,0050 ; \mathrm{C}_{5}-0,0075\right.$ e $\left.\mathrm{C}_{6}-0,0100 \mathrm{~g} \mathrm{~L}^{-1}\right)$.

As variáveis do material combustível indicam que na região a carga depositada é devido à abscisão de folhas para redução da evapotranspiração durante a estação seca (ESTIARTE; PEÑUELAS, 2014; VIERA et al., 2014), em conjunto com teores de umidade abaixo de $25,0 \%$, aumentam os riscos de ocorrências de incêndios florestais nas áreas de eucalipto (SOARES; BATISTA, 2007). 


\section{Descrição das variáveis meteorológicas}

Os elementos meteorológicos apresentaram poucas variações no momento das queimas controladas realizadas com aplicações de água e dos retardantes Phos-Chek WD881 ${ }^{\circledR}$, Hold Fire ${ }^{\circledR}$ e Nutrigel ${ }^{\circledR}$, evidenciando condições microclimáticas semelhantes nas parcelas. Os valores médios de temperatura do ar, umidade relativa do ar e velocidade do vento para o retardante Phos-Chek WD881 ${ }^{\circledR}$ variaram de 30,4 a $34,3^{\circ} \mathrm{C} ; 20,0$ a $35,0 \% ; 0$ a 1,6 $\mathrm{m} \mathrm{s}^{-1}$ (Tabela 2); para o retardante Hold Fire ${ }^{\circledR}$ variaram de 31,2 a $34,9^{\circ} \mathrm{C} ; 19,0$ a $29,0 \% ; 0$ a $1,7 \mathrm{~m} \mathrm{~s}^{-1}$ e para o Nutrigel ${ }^{\circledR}$ variaram de 28,7 a $34,6^{\circ} \mathrm{C} ; 21,0$ a $32,0 \%$ e 0 a $1,9 \mathrm{~m} \mathrm{~s}^{-1}$ (dados não apresentados, por apresentarem comportamento semelhante ao ocorrido na Tabela 2 ).

A interação entre as características do microclima e do material combustível demonstraram os riscos e perigos de ocorrências de incêndios florestais na área de Eucalyptus urograndis no período avaliado. A atuação em conjunto dos fatores aumentou a flamabilidade do material combustível e consequentemente as chances de ignição e propagação do fogo na área (HOFFMANN et al., 2012).

Tabela 2 - Variáveis meteorológicas monitoradas no momento das queimas controladas com o retardante Phos-Chek WD881 ${ }^{\circledR}$, em área de Eucalyptus urograndis (clone H13), no município de Sorriso - MT, Brasil

Table 2 - Meteorological variables monitored controlled burning with Phos-Chek WD881 ${ }^{\circledR}$ fire retardant in Eucalyptus urograndis (clone H13) area, in the municipality of Sorriso - MT state,

Brazil

\begin{tabular}{|c|c|c|c|c|c|c|c|c|c|c|}
\hline \multirow{2}{*}{$\begin{array}{c}\text { Concentração } \\
\left(\mathbf{m L ~ L}^{-1}\right)\end{array}$} & \multirow{2}{*}{$\begin{array}{c}\mathbf{V C} \\
\left(\mathbf{L} \mathbf{~ m}^{-2}\right)\end{array}$} & \multicolumn{3}{|c|}{$\mathbf{T}\left({ }^{\circ} \mathbf{C}\right)$} & \multicolumn{3}{|c|}{ UR (\%) } & \multicolumn{3}{|c|}{$\mathbf{V V}\left(\mathbf{m ~ s}^{-1}\right)$} \\
\hline & & Méd & Máx & Min & Méd & Máx & Min & Méd & Máx & Min \\
\hline $\mathbf{0 , 0}$ & \multirow{6}{*}{0,5} & 33,8 & 33,8 & 33,7 & 22,5 & 23,0 & 22,0 & 1,0 & 1,7 & 0,3 \\
\hline 0,1 & & 31,9 & 31,9 & 31,9 & 27,0 & 27,0 & 27,0 & 1,4 & 1,7 & 1,0 \\
\hline 0,3 & & 30,4 & 30,6 & 30,2 & 27,5 & 28,0 & 27,0 & 1,6 & 1,7 & 1,4 \\
\hline 0,6 & & 31,9 & 32,0 & 31,8 & 25,0 & 26,0 & 24,0 & 0,9 & 1,7 & 0,0 \\
\hline 0,8 & & 33,0 & 33,2 & 32,7 & 20,0 & 20,0 & 20,0 & 1,2 & 1,4 & 1,0 \\
\hline 1,0 & & 32,8 & 32,9 & 32,6 & 22,5 & 23,0 & 22,0 & 1,6 & 1,7 & 1,4 \\
\hline 0,0 & \multirow{6}{*}{1,0} & 34,0 & 34,1 & 33,9 & 21,5 & 22,0 & 21,0 & 1,1 & 1,4 & 0,7 \\
\hline 0,1 & & 32,9 & 33,1 & 32,6 & 20,5 & 22,0 & 19,0 & 1,1 & 1,4 & 0,7 \\
\hline 0,3 & & 32,3 & 32,3 & 32,2 & 25,0 & 26,0 & 24,0 & 0,9 & 1,4 & 0,3 \\
\hline 0,6 & & 32,5 & 32,9 & 32,1 & 20,5 & 21,0 & 20,0 & 1,4 & 1,7 & 1,0 \\
\hline 0,8 & & 31,2 & 31,4 & 30,9 & 30,5 & 31,0 & 30,0 & 0,0 & 0,0 & 0,0 \\
\hline 1,0 & & 32,2 & 32,2 & 32,1 & 25,0 & 26,0 & 24,0 & 1,2 & 1,7 & 0,7 \\
\hline 0,0 & \multirow{5}{*}{2,0} & 32,7 & 32,7 & 32,6 & 23,0 & 23,0 & 23,0 & 0,0 & 0,0 & 0,0 \\
\hline 0,1 & & 34,3 & 34,4 & 34,1 & 19,5 & 21,0 & 18,0 & 0,7 & 1,0 & 0,3 \\
\hline 0,6 & & 32,5 & 32,5 & 32,4 & 29,0 & 29,0 & 29,0 & 0,7 & 0,7 & 0,7 \\
\hline 0,8 & & 31,7 & 31,9 & 31,4 & 31,5 & 32,0 & 31,0 & 0,0 & 0,0 & 0,0 \\
\hline 1,0 & & 30,5 & 30,7 & 30,3 & 35,0 & 37,0 & 33,0 & 0,9 & 1,0 & 0,7 \\
\hline
\end{tabular}

Fonte: Autores (2019)

Em que: VC: Volume de calda de água; T: temperatura do ar; UR: umidade relativa do ar; VV: velocidade do vento; méd: média; máx.: máxima; min: mínima. *Concentração de $0,0 \mathrm{~mL} \mathrm{~L}^{-1}$ ou g $\mathrm{L}^{-1}$ considera apenas a aplicação de água, enquanto nas demais concentrações consideram-se os retardantes dissolvidos em água. 


\section{Comportamento do fogo}

O comportamento do fogo representado pela velocidade de propagação do fogo e o comprimento das chamas referentes aos retardantes Phos-Chek WD881 ${ }^{\circledR}$, Hold Fire ${ }^{\circledR}$ e Nutrigel ${ }^{\circledR}$, apresentaram diferenças entre os tratamentos no desdobramento do fatorial duplo de concentrações e volumes de calda aplicados (Tabela 3). As análises fatoriais indicaram interação entre os fatores, confirmando que o modo de preparação e aplicação dos retardantes sobre o material combustível influenciaram diretamente na eficiência dos produtos.

Em todos os retardantes, as variáveis do comportamento do fogo analisadas foram maiores nos tratamentos-controle (sem aplicação de retardante ou água) devido aos baixos teores de umidade do material combustível nas condições reais da área. Nos controles, os valores médios de VP foram de 0,71; 0,77 e $0,73 \mathrm{~m} \mathrm{~min}^{-1}$ e do L de 90,00; 85,44 e $86,76 \mathrm{~cm}$ para o Phos-Chek WD881 ${ }^{\circledR}$, Hold Fire ${ }^{\circledR}$ e Nutrigel ${ }^{\circledR}$, respectivamente. Os valores do controle corroboram os de Alves et al. (2017) em queimas controladas de Eucalyptus urograndis com 4,5 anos com VP de 0,74 $\mathrm{m} \mathrm{min}^{-1} \mathrm{e} L$ de $100 \mathrm{~cm}$, assim como Lima et al. (2017) na

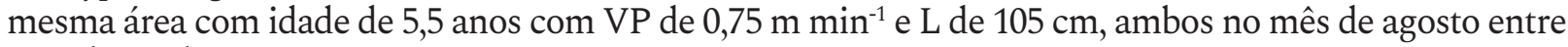
as $10 \mathrm{he} 14 \mathrm{~h}$.

Nas parcelas com aplicação apenas de água (concentração de $0 \%$ ) ocorreu a redução das variáveis do comportamento do fogo em relação ao tratamento-controle, indicando aumento da eficiência da água com o incremento do volume de calda aplicado. Na calda de $0,5 \mathrm{~L} \mathrm{~m}^{-2}$, a VP foi de $0,52 \mathrm{~m} \mathrm{~min}^{-1}$ e L de $86,66 \mathrm{~cm}$, entretanto, aplicando $2,0 \mathrm{~L} \mathrm{~m}^{-2}$ houve redução da VP para $0,20 \mathrm{~m} \mathrm{~min}^{-1} \mathrm{e}$ do $\mathrm{L}$ para $32,50 \mathrm{~cm}$. Contudo, a água foi menos eficiente que as demais concentrações dos retardantes devido ao início da sua evaporação do material combustível nas condições ambientais da área (RIBEIRO et al., 2006; PLUCINSKI; SULLIVAN; HURLEY, 2017).

Em relação às concentrações dos retardantes, o incremento do volume de calda melhorou a eficiência dos produtos. No volume de calda de $0,5 \mathrm{~L} \mathrm{~m}^{-2}$, o retardante Phos-Chek WD881 ${ }^{\circledR}$ apresentou melhor eficiência na concentração de $1,0 \mathrm{~mL} \mathrm{~L}^{-1}$ com VP de $0,25 \mathrm{~m} \mathrm{~min}^{-1}$ e L de $30 \mathrm{~cm}$; o Hold Fire ${ }^{\circledR}$ na concentração de $1,5 \mathrm{~mL} \mathrm{~L}^{-1}$ com VP de $0,33 \mathrm{~m} \mathrm{~min}^{-1}$ e L de $43,33 \mathrm{~cm}$; e o Nutrigel ${ }^{\circledR}$ nas concentrações de 0,0050 e $0,0075 \mathrm{~g} \mathrm{~L}^{-1}$, sendo que a concentração de $0,0050 \mathrm{~g} \mathrm{~L}^{-1}$ apresentou VP de $0,22 \mathrm{~m} \mathrm{~min}^{-1} \mathrm{e} \mathrm{L} \mathrm{de} 40 \mathrm{~cm}$. Entretanto, aplicando o volume de calda de $2,0 \mathrm{~L} \mathrm{~m}^{-2}$ nas concentrações mais eficientes dos retardantes $\left(1,0 \mathrm{~mL} \mathrm{~L}^{-1} ; 1,5 \mathrm{~mL} \mathrm{~L}^{-1}\right.$ e $0,0050 \mathrm{~g} \mathrm{~L}^{-1}$ para o Phos-Chek WD881 ${ }^{\circledR}$, Hold Fire ${ }^{\circledR}$ e Nutrigel ${ }^{\circledR}$, respectivamente) foram observadas à máxima eficiência dos produtos com a extinção do fogo nas parcelas.

Tabela 3 - Velocidade de propagação do fogo e comprimento das chamas em queimas controladas com diferentes concentrações e volumes de calda de retardantes de fogo, em áreas de Eucalyptus urograndis (clone H13), no município de Sorriso - MT, Brasil

Table 3 - Fire propagation speed and flame length in controlled burning with different concentrations and volumes of fire retardant syrup in Eucalyptus urograndis (clone H13) area, in the municipality of Sorriso - MT state, Brazil

\begin{tabular}{|c|c|c|c|c|c|c|}
\hline \multirow{2}{*}{$\begin{array}{l}\text { Concentração } \\
\left(\mathbf{m L} \mathbf{L}^{-1} \mathbf{e} \mathbf{g ~ L}^{-1}\right)\end{array}$} & \multicolumn{3}{|c|}{$\mathbf{V P}\left(\mathbf{m} \mathbf{m i n}^{-1}\right)$} & \multicolumn{3}{|c|}{$\mathbf{L}(\mathbf{c m})$} \\
\hline & $0,5 \mathrm{~L} \mathrm{~m}^{-2}$ & $1,0 \mathrm{~L} \mathrm{~m}^{-2}$ & $2,0 \mathrm{~L} \mathrm{~m}^{-2}$ & $0,5 \mathrm{~L} \mathrm{~m}^{-2}$ & $1,0 \mathrm{~L} \mathrm{~m}^{-2}$ & $2,0 \mathrm{~L} \mathrm{~m}^{-2}$ \\
\hline \multicolumn{7}{|c|}{ Phos-Chek WD881 ${ }^{\circledR}$} \\
\hline Controle & $0,71 \mathrm{Da}$ & $0,71 \mathrm{Ba}$ & $0,71 \mathrm{Ca}$ & $90,00 \mathrm{Da}$ & $90,00 \mathrm{Ca}$ & $90,00 \mathrm{Da}$ \\
\hline 0,0 & $0,52 \mathrm{Cb}$ & $0,39 \mathrm{Ab}$ & $0,20 \mathrm{Ba}$ & $86,66 \mathrm{Dc}$ & $70,00 \mathrm{Bb}$ & $32,50 \mathrm{Ba}$ \\
\hline 0,1 & $0,43 \mathrm{Bb}$ & $0,28 \mathrm{Aa}$ & $0,25 \mathrm{Ba}$ & $70,00 \mathrm{Cb}$ & $56,66 \mathrm{Aa}$ & $53,33 \mathrm{Ca}$ \\
\hline 0,3 & $0,28 \mathrm{Aa}$ & $0,22 \mathrm{Aa}$ & - & $53,33 \mathrm{Ba}$ & $50,00 \mathrm{Aa}$ & - \\
\hline 0,6 & $0,24 \mathrm{Aa}$ & $0,25 \mathrm{Aa}$ & $0,19 \mathrm{Ba}$ & 33,33 Aa & $50,00 \mathrm{Ab}$ & $23,33 \mathrm{Ba}$ \\
\hline 0,8 & $0,28 \mathrm{Ab}$ & $0,19 \mathrm{Ab}$ & $0,00 \mathrm{Aa}$ & $50,30 \mathrm{Bb}$ & $50,00 \mathrm{Ab}$ & $0,00 \mathrm{Aa}$ \\
\hline 1,0 & $0,25 \mathrm{Ab}$ & $0,15 \mathrm{Ab}$ & $0,00 \mathrm{Aa}$ & $30,00 \mathrm{Ab}$ & $40,00 \mathrm{Ab}$ & $0,00 \mathrm{Aa}$ \\
\hline
\end{tabular}


Tabela 3 - Conclusão ...

Table 3 - Conclusion ...

\begin{tabular}{|c|c|c|c|c|c|c|}
\hline \multirow{2}{*}{$\begin{array}{l}\text { Concentração } \\
\left(\mathbf{m} \mathbf{L} \mathbf{L}^{-1} \mathbf{e} \mathbf{g} \mathbf{L}^{-1}\right)\end{array}$} & \multicolumn{3}{|c|}{$\mathbf{V P}\left(\mathbf{m} \mathbf{m i n}^{-1}\right)$} & \multicolumn{3}{|c|}{$\mathbf{L}(\mathbf{c m})$} \\
\hline & $0,5 \mathrm{~L} \mathrm{~m}^{-2}$ & $1,0 \mathrm{~L} \mathrm{~m}^{-2}$ & $2,0 \mathrm{~L} \mathrm{~m}^{-2}$ & $0,5 \mathrm{~L} \mathrm{~m}^{-2}$ & $1,0 \mathrm{~L} \mathrm{~m}^{-2}$ & $2,0 \mathrm{~L} \mathrm{~m}^{-2}$ \\
\hline \multicolumn{7}{|l|}{ Hold Fire ${ }^{\circledR}$} \\
\hline Controle & $0,77 \mathrm{Ca}$ & $0,77 \mathrm{Ca}$ & $0,77 \mathrm{Ca}$ & $85,44 \mathrm{Da}$ & $85,44 \mathrm{Ca}$ & $85,44 \mathrm{Da}$ \\
\hline $\mathbf{0 , 0}$ & $0,52 \mathrm{Bb}$ & $0,39 \mathrm{Bb}$ & $0,20 \mathrm{Ba}$ & $86,66 \mathrm{Dc}$ & $70,00 \mathrm{Bb}$ & $32,50 \mathrm{Ca}$ \\
\hline 0,7 & $0,36 \mathrm{Ab}$ & $0,37 \mathrm{Bb}$ & $0,18 \mathrm{Ba}$ & $70,00 \mathrm{Cc}$ & $55,00 \mathrm{Ab}$ & $13,33 \mathrm{Ba}$ \\
\hline 0,9 & $0,32 \mathrm{Ab}$ & $0,20 \mathrm{Aa}$ & $0,19 \mathrm{Ba}$ & $66,67 \mathrm{Cb}$ & $38,33 \mathrm{Aa}$ & $28,33 \mathrm{Ca}$ \\
\hline 1,1 & $0,36 \mathrm{Ab}$ & $0,27 \mathrm{Ab}$ & $0,13 \mathrm{Ba}$ & $60,00 \mathrm{Bb}$ & $50,00 \mathrm{Ab}$ & $11,66 \mathrm{Ba}$ \\
\hline 1,3 & $0,37 \mathrm{Ac}$ & $0,17 \mathrm{Ab}$ & $0,00 \mathrm{Aa}$ & $41,67 \mathrm{Ab}$ & $40,00 \mathrm{Ab}$ & $0,00 \mathrm{Aa}$ \\
\hline 1,5 & $0,33 \mathrm{Ac}$ & $0,18 \mathrm{Ab}$ & $0,00 \mathrm{Aa}$ & $43,33 \mathrm{Ab}$ & $43,33 \mathrm{Ab}$ & $0,00 \mathrm{Aa}$ \\
\hline \multicolumn{7}{|l|}{ Nutrigel ${ }^{\circledR}$} \\
\hline Controle & $0,73 \mathrm{Da}$ & $0,73 \mathrm{Ca}$ & $0,73 \mathrm{Ca}$ & $86,76 \mathrm{Da}$ & $86,76 \mathrm{Da}$ & $86,76 \mathrm{Da}$ \\
\hline $\mathbf{0 , 0}$ & $0,52 \mathrm{Cc}$ & $0,39 \mathrm{Bb}$ & $0,20 \mathrm{Ba}$ & $86,66 \mathrm{Dc}$ & $70,00 \mathrm{Cb}$ & $32,50 \mathrm{Ca}$ \\
\hline 0,0010 & $0,38 \mathrm{Bb}$ & $0,24 \mathrm{Aa}$ & $0,17 \mathrm{Ba}$ & $80,00 \mathrm{Dc}$ & $51,67 \mathrm{Bb}$ & $30,00 \mathrm{Ca}$ \\
\hline 0,0025 & $0,35 \mathrm{Bb}$ & $0,21 \mathrm{Aa}$ & $0,13 \mathrm{Ba}$ & $70,00 \mathrm{Cc}$ & $50,00 \mathrm{Bb}$ & $15,00 \mathrm{Ba}$ \\
\hline 0,0050 & $0,22 \mathrm{Ab}$ & $0,18 \mathrm{Ab}$ & $0,00 \mathrm{Aa}$ & $40,00 \mathrm{Ab}$ & $30,00 \mathrm{Ab}$ & $0,00 \mathrm{Aa}$ \\
\hline 0,0075 & $0,29 \mathrm{Ac}$ & $0,16 \mathrm{Ab}$ & $0,00 \mathrm{Aa}$ & $58,33 \mathrm{Bc}$ & $30,00 \mathrm{Ab}$ & $0,00 \mathrm{Aa}$ \\
\hline 0,0100 & $0,25 \mathrm{Aa}$ & $0,22 \mathrm{Aa}$ & $0,13 \mathrm{Ba}$ & $70,00 \mathrm{Cb}$ & $35,33 \mathrm{Aa}$ & $23,33 \mathrm{Ba}$ \\
\hline
\end{tabular}

Fonte: Autores (2019)

Em que: *Concentração de $0 \mathrm{~mL} \mathrm{~L}^{-1}$ ou g L ${ }^{-1}$ considera-se apenas a aplicação de água, enquanto nas demais concentrações consideram-se os retardantes dissolvidos em água; médias seguidas da mesma letra na linha (minúscula) e na coluna (maiúscula) não diferiram entre si pelo teste de Scott Scott-Knott a 5,0\% de significância. Em que: VP: velocidade de propagação do fogo, L: comprimento das chamas, Controle: parcela sem aplicação de retardante/água.

As taxas de reduções da velocidade de propagação do fogo (TRVP) e comprimento das chamas (TRL) dos retardantes apresentaram comportamentos dependentes do tratamentocontrole, com tendência de redução similar ao comportamento do fogo. Dessa forma, as taxas de reduções aumentaram conforme a combinação entre incremento do volume de calda e a concentração ideal inerente de cada retardante, com destaque no volume de calda de $2,0 \mathrm{~L} \mathrm{~m}^{-2}$ (Figura 1).

Com base nas concentrações predeterminadas de cada retardante, foram obtidas as concentrações ideais para os produtos por meio de modelos (equações matemáticas) gerados em análises de regressões (Figura 2). Assim sendo, os retardantes Phos-Chek WD881 ${ }^{\circledR}$ e Hold Fire ${ }^{\circledR}$ apresentaram melhores ajustes nos modelos lineares (correlações superiores a 81,0\%), indicando que o aumento da concentração melhorou a eficiência dos retardantes. Entretanto, para o Nutrigel ${ }^{\circledR}$ o modelo com melhor ajuste foi polinomial quadrático indicando uma concentração máxima ideal (acima ou abaixo perde eficiência) para a eficiência do retardante (correlações superiores a 90,0\%). 
Figura 1 - Taxas de reduções da velocidade de propagação do fogo (TRVP) e comprimento das chamas (TRL) em queimas controladas com diferentes concentrações e volumes de calda de retardantes de fogo, em área de Eucalyptus urograndis (clone H13), no município de Sorriso - MT, Brasil

Figure 1 - Fire propagation speed rate (TRVP) and flame length (TRL) in controlled burning with different concentrations and volumes of fire retardant syrup in Eucalyptus urograndis (clone H13) area, in the municipality of Sorriso - MT state, Brazil

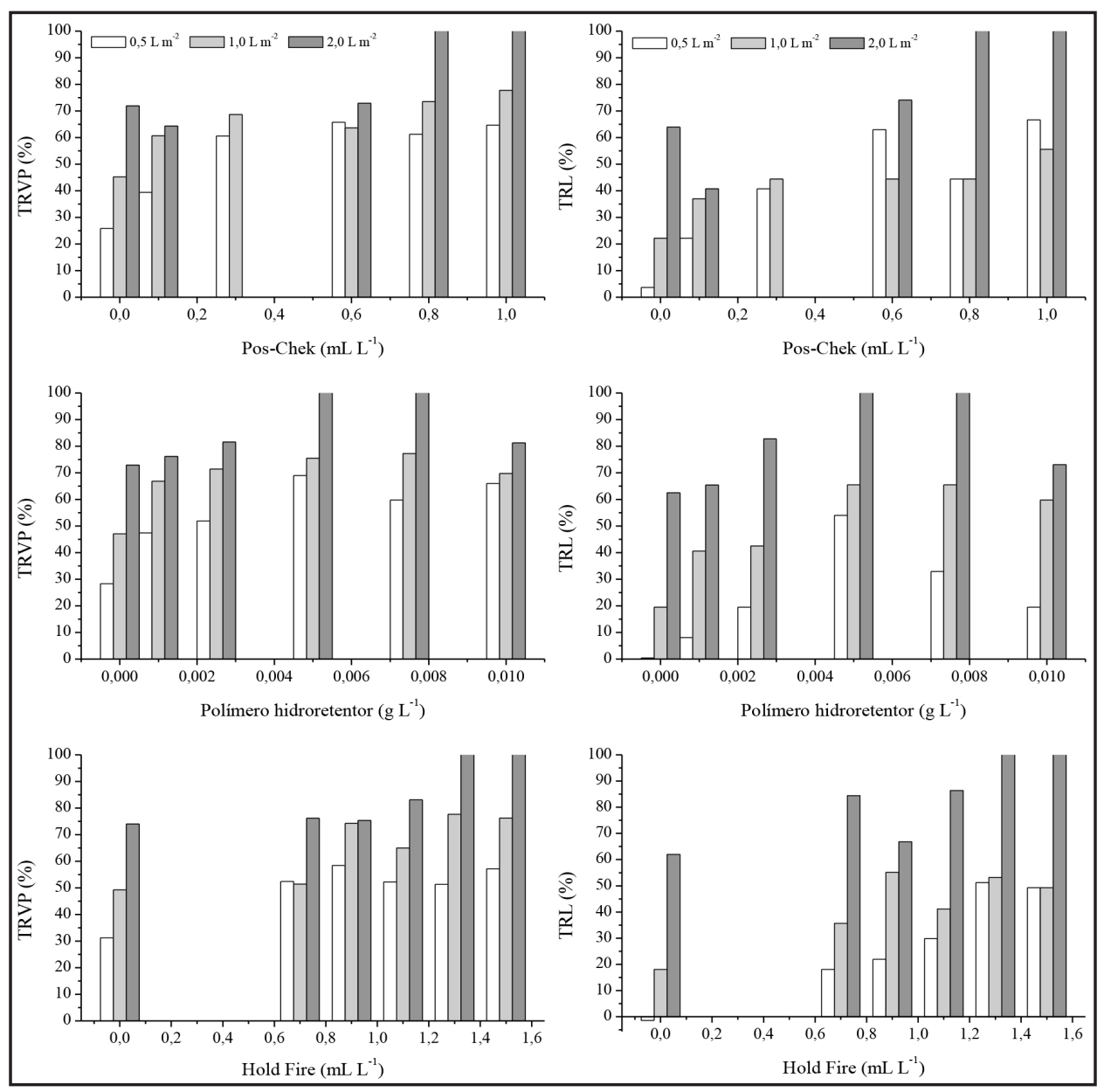

Fonte: Autores (2019)

Por meio de modelos lineares foi definida a concentração ideal dos retardantes para a máxima eficiência na redução do comportamento do fogo, sendo para o Phos-Chek WD881 ${ }^{\circledR}$ a concentração de $1,0 \mathrm{~mL} \mathrm{~L}^{-1}$ e para o Hold Fire ${ }^{\circledR} 1,5 \mathrm{~mL} \mathrm{~L}^{-1}$, ambos no volume de calda de $2,0 \mathrm{~L} \mathrm{~m}^{-2}$. O aumento da eficiência dos retardantes com o incremento da concentração dos produtos foi observado em outros estudos, como de Fiedler et al. (2015) utilizando os retardantes Phos-chek WD881 ${ }^{\circledR}, \mathrm{RFC}{ }^{\circledR}, \mathrm{F}^{\circ}{ }^{\circledR}{ }^{\circledR}$ e HMIS 1-0-0 $\mathrm{DPnb}^{\circledR}$, no volume de calda de $0,5 \mathrm{~L} \mathrm{~m}^{-2} \mathrm{em}$ queimas controladas de Melinis minutiflora P. Beauv., encontraram máxima eficiência na maior concentração aplicada de $1,5 \mathrm{~mL} \mathrm{~L}^{-1}$. Assim como, Canzian et al. (2016) com uso do retardante Phos-Chek (longa-duração) aplicado na calda de $0,5 \mathrm{~L} \mathrm{~m}^{-2} \mathrm{em}$ área de Eucalyptus urograndis, com máxima redução do comportamento do fogo na maior concentração aplicada de $3,0 \%$.

Entretanto, para o retardante Nutrigel ${ }^{\circledR}$, o modelo polinomial quadrático indicou máxima eficiência na concentração de $0,0060 \mathrm{~g} \mathrm{~L}^{-1}$, também no volume de calda de $2,0 \mathrm{~L} \mathrm{~m}^{-2}$. Diferente da tendência dos outros retardantes (máxima eficiência com aumento da concentração), o Nutrigel ${ }^{\circledR}$ apresentou um ponto de máxima eficiência em uma concentração intermediária, característica importante para redução de desperdícios de produto.

Foi observada a diminuição da eficácia do Nutrigel ${ }^{\circledR}$ na maior concentração de 0,0100 
$\mathrm{g} \mathrm{L}^{-1}$, devido à mudança da estrutura física do retardante (liquída para gelatinosa/grumos de gel) após a aplicação sobre o material combustível. A aglomeração de moléculas gerada por essa concentração inibiu a penetração do retardante entre o material combustível, assim, durante as queimas controladas, o fogo continuou se propagando, lentamente, o que afetou a redução do comportamento do fogo comparada às concentrações inferiores $(0,0050$ e $0,0075 \mathrm{~g}$ $\mathrm{L}^{-1}$. Essa estrutura gelatinosa do $\mathrm{Nutrigel}^{\circledR}$ em altas concentrações é esperada em polímeros hidrorretentores, que diluídos em água absorvem umidade e mudam sua estrutura física (cristais de sais para gel) (BALENA, 1998; GUILHERME et al., 2015).

Figura 2 - Regressões lineares e polinomiais quadráticas entre o incremento das concentrações dos retardantes do fogo e: velocidade de propagação do fogo (VP), comprimento das chamas $(L)$, taxa de redução da VP (TRVP) e taxa de redução do $L$ (TRL), nos volumes de calda aplicados de $0,5 \mathrm{~L} \mathrm{~m}^{-2}$ (quadrado com linha preta), $1,0 \mathrm{~L} \mathrm{~m}^{-2}$ (círculo com linha vermelha) e $2,0 \mathrm{~L} \mathrm{~m}^{-2}$ (triângulo com linha azul), em queimas controladas de Eucalyptus urograndis (clone H13) no município de Sorriso - MT, Brasil

Figure 2 - Linear and polynomial quadratic regressions between fire retardant concentrations and fire propagation speed (PV), flame length (L), rate of reduction of PV (LVP) and rate of reduction of $\mathrm{L}$ (TRL), in the volumes of syrup of $0.5 \mathrm{~L} \mathrm{~m}^{-2}$ (square with black line), $1.0 \mathrm{~L} \mathrm{~m}^{-2}$ (circle with red line) and $2.0 \mathrm{~L} \mathrm{~m}^{-2}$ (triangle with blue line), applied in controlled burning of Eucalyptus urograndis (clone H13), in the municipality of Sorriso - MT state, Brazil

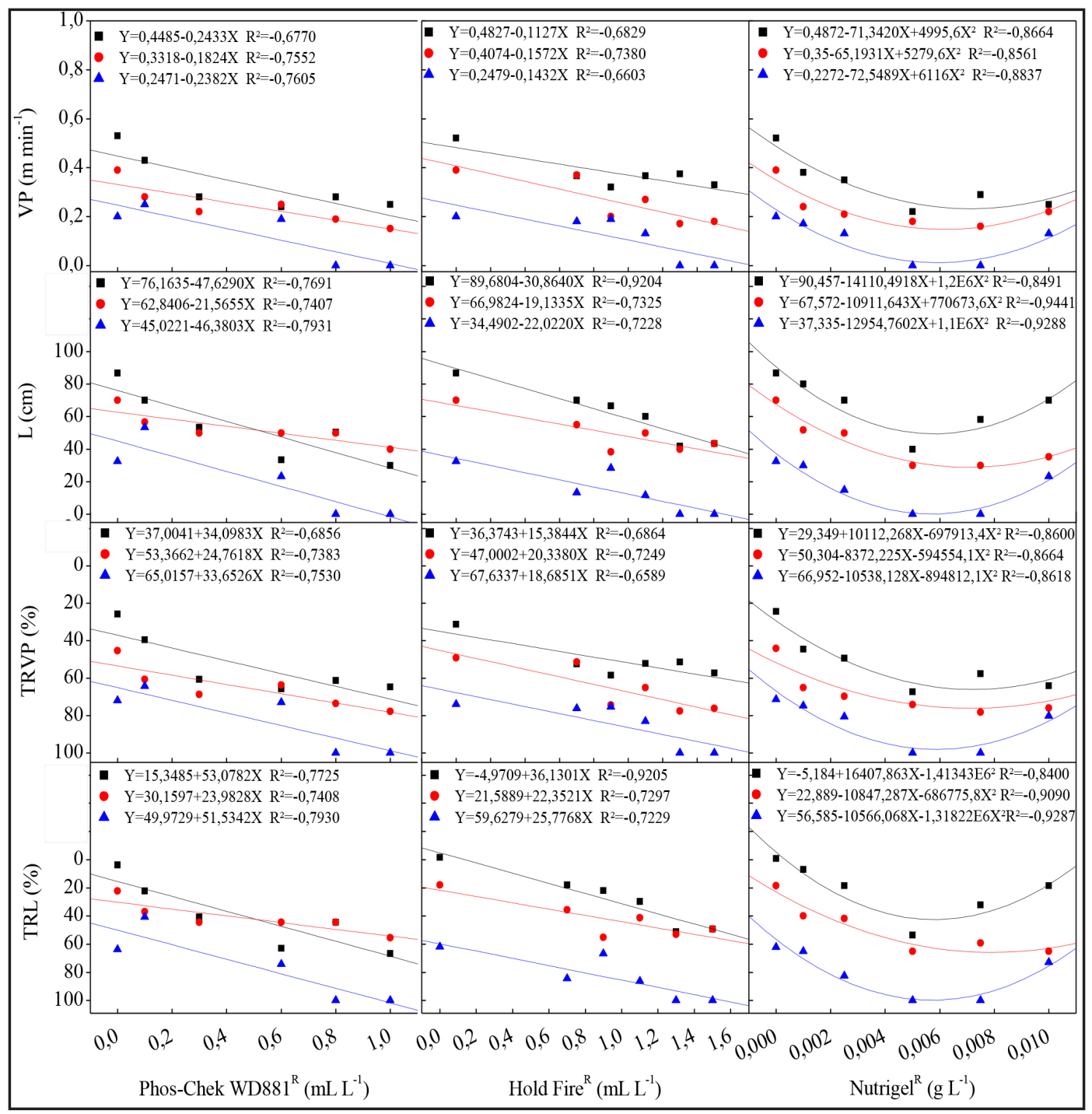

Fonte: Autores (2019) 
Todos os retardantes apresentaram a redução do comportamento do fogo nos volumes de calda de 0,5 e $1,0 \mathrm{~L} \mathrm{~m}^{-2}$. Entretanto, como esperado, o aumento do volume de calda para 2,0 L $\mathrm{m}^{-2}$ em conjunto com as concentrações ideais de cada retardante gerou a extinção do fogo nas áreas de Eucalyptus urograndis, indicando que o volume de calda determina a máxima eficiência dos retardantes no combate a incêndios florestais. Esse comportamento também foi relatado por Ribeiro et al. (2006) com uso do Phos-Chek ${ }^{\circledR}$ (longa duração) na concentração de $13,4 \mathrm{~mL} \mathrm{~L}^{-1}$, com redução do comportamento do fogo (intensidade) de $44,0 \%$ no volume de calda de $0,3 \mathrm{~L} \mathrm{~m}^{-2}$ e $96,0 \%$ na calda de $1,2 \mathrm{~L} \mathrm{~m}^{-2}$.

No levantamento do percentual de material combustível remanescente pós-queima (Figura 3), foram observadas poucas variações nos volumes de calda aplicados de 0,5 e $1,0 \mathrm{~L} \mathrm{~m}^{-2}$. Contudo, na aplicação da calda de $2,0 \mathrm{~L} \mathrm{~m}^{-2}$ foi observada uma tendência de aumento do material combustível remanescente e, em contrapartida, a redução do material consumido nas parcelas.

Figura 3 - Material combustível pós-queima nos volumes de calda e concentrações de retardantes do fogo em queimas controladas em área de Eucalyptus urograndis (clone H13), no município de Sorriso - MT, Brasil

Figure 3 - Post-burning fuel material in the volumes of syrup and concentrations of fire retardants in controlled burning in Eucalyptus urograndis (clone H13) area, in the municipality of Sorriso - MT state, Brazil

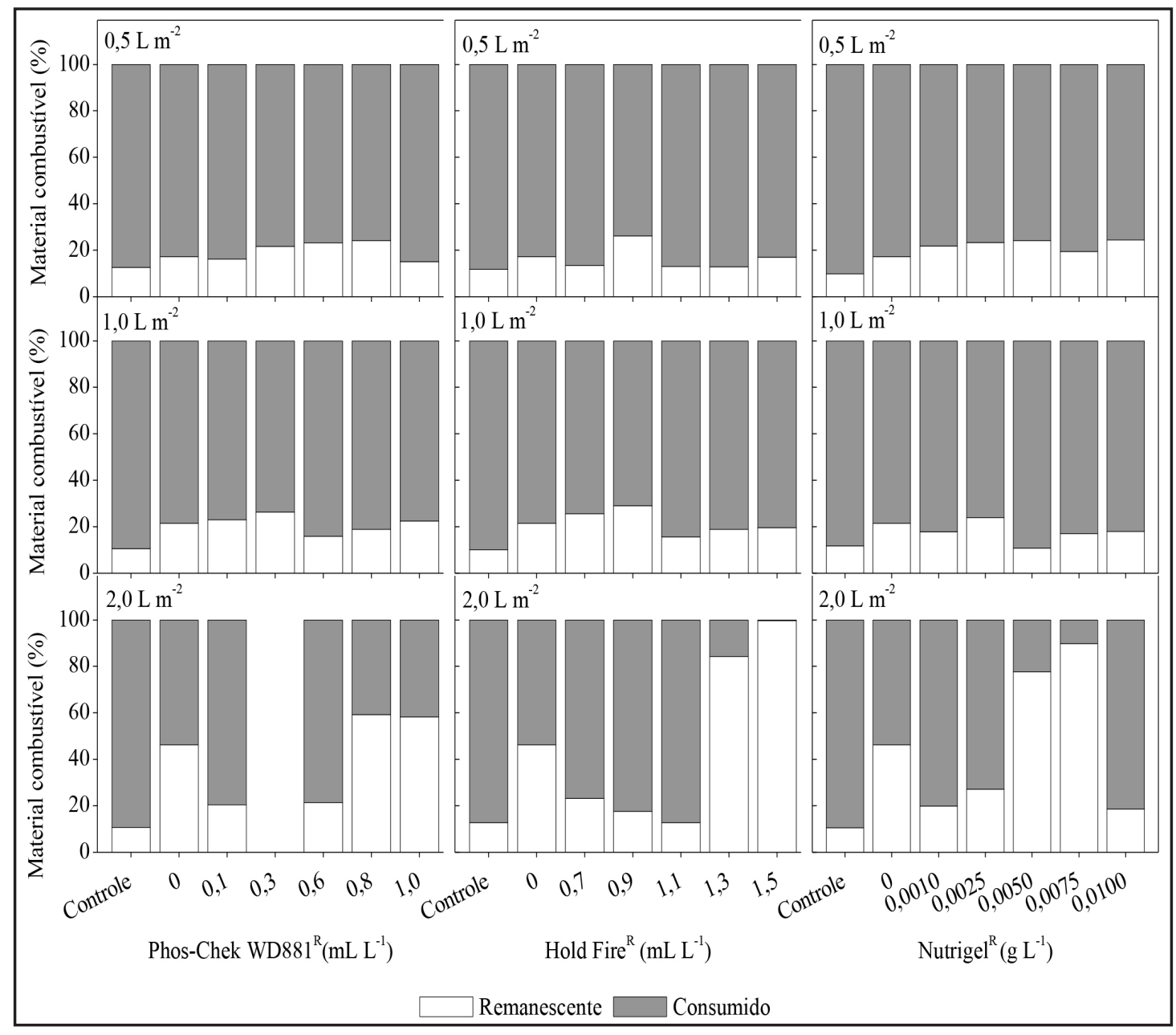

Fonte: Autores (2019) 
A percentagem de material combustível consumido no tratamento-controle foi superior a 95,0\% para as parcelas dos três retardantes avaliados. Valor similar foi observado por Alves et al. (2017) em queimas controladas em área de Eucalyptus urograndis (clone H13) com 4,5 anos de idade em agosto, com 95,62\% de material consumido em queimas controladas sem uso de retardantes do fogo.

Entretanto, considerando as aplicações das concentrações dos retardantes, o percentual de material combustível remanescente apresentou poucas variações nos volumes de calda de $0,5 \mathrm{e}$ $1,0 \mathrm{~L} \mathrm{~m}^{-2}$, comportamento esperado, uma vez que nos menores volumes de calda aplicados o fogo continuou se propagando sobre o material combustível, mais lentamente, como observado nas variáveis descritivas do comportamento do fogo. Em contrapartida, quando aplicado o volume de calda de $2,0 \mathrm{~L} \mathrm{~m}^{-2}$ nas concentrações mais eficientes de cada retardante, ocorreu a extinção do fogo nas parcelas. Dessa forma, o material combustível remanescente foi de aproximadamente 60,0; 98,0 e 90,0\% nas parcelas de Phos-Chek WD881 ${ }^{\circledR}$, Hold Fire ${ }^{\circledR}$ e Nutrigel $^{\circledR}$, respectivamente.

O efeito do volume de calda na redução do material combustível consumido também foi reportado por Batista et al. (2008) em queimas controladas em área de Pinus taeda L., após 24 h de aplicação de um retardante à base de polifosfatos amônicos (longa duração) no volume de calda de $0,5 \mathrm{~L} \mathrm{~m}^{-2}$ com aproximadamente $32,0 \%$ de material combustível consumido, todavia, aplicando a calda de $1,0 \mathrm{~L} \mathrm{~m}^{-2}$ não houve consumo de material combustível $(0 \%)$ nas áreas. Assim como Ribeiro et al. (2006) em queimas controladas de Brachiaria decumbens Stapf, o material combustível consumido foi menor no volume de calda de $1,2 \mathrm{~L} \mathrm{~m}^{-2}$ comparado ao de $0,5 \mathrm{~L} \mathrm{~m}^{-2}$.

A aplicação de volumes de calda menores nas concentrações mais eficazes dos retardantes do fogo é essencial em áreas com limitação de recursos hídricos para o abastecimento. Dessa forma, o fogo, ao chegar nos aceiros químicos, tende a reduzir, condição que facilitaria o combate direto às chamas pelos brigadistas (PLUCINSKI; PARDO, 2013; FIEDLER et al., 2015). Entretanto, a aplicação de um volume de calda maior é relevante em áreas com disponibilidade de recursos hídricos para a captação de água, condição que evitaria riscos no combate direto pelos brigadistas, economia de tempo e redução de desperdícios de retardantes do fogo (RIBEIRO et al., 2006; CANZIAN et al., 2018).

\section{Conclusão}

Os retardantes empregados são eficientes na redução e/ou extinção das variáveis do comportamento do fogo analisadas (velocidade de propagação do fogo e comprimento das chamas) em queimas controladas em material combustível de Eucalyptus urograndis (clone H13), com 6,0 anos de idade.

O incremento do volume de calda aumenta a eficiência dos retardante de fogo, entretanto, salienta-se que a disponibilidade de água pode ser um fator limitante no combate a incêndios florestais, condição relevante nas tomadas de decisões com as recomendações dos retardantes.

A recomendação de uso prático para os retardantes na sua máxima eficiência é: PhosChek WD881 ${ }^{\circledR}$ na concentração de $1,0 \mathrm{~mL} \mathrm{~L}^{-1}$, Hold Fire ${ }^{\circledR}$ na concentração de $1,5 \mathrm{~mL} \mathrm{~L}^{-1}$ e Nutrigel ${ }^{\circledR}$ na concentração de $0,0060 \mathrm{~g} \mathrm{~L}^{-1}$, ambos no volume de calda de $2,0 \mathrm{~L} \mathrm{~m}^{-2}$ após uma hora de aplicação sobre o material combustível. 


\section{Agradecimentos}

À Coordenação de Aperfeiçoamento de Pessoal de Nível Superior (CAPES) - Código de Financiamento 001. À Empresa Brasil Foods S.A (BRF) pela disponibilidade da área de eucalipto para a realização do experimento. À Universidade Federal de Mato Grosso (UFMT), Campus de Sinop pelo apoio logístico. Ao José Renato Favaro pela doação do produto Hold Fire ${ }^{\circledR}$ para o desenvolvimento do experimento.

\section{Referências}

ALVES, L. J. S. et al. Fire Behavior in Eucalyptus urograndis (Clone H13) Forest in CerradoAmazon Transition, Brazil. Australian Journal of Basic and Applied Sciences, [s. l.], v. 11, n. 4, p. 60-71, 2017.

BALENA, S. P. Efeito de polímeros hidrorretentores nas propriedades físicas e hidráulicos de dois meios porosos. 1998. Dissertação (Mestrado) - Universidade Federal do Paraná, Curitiba, 1998.

BARLOW, J. et al. Litter fall and decomposition in primary, secondary and plantation forests in the Brazilian Amazon. Forest Ecology and Management, Amsterdam, v. 247, p. 91-97, 2007.

BATISTA, A. C. et al. Avaliação da eficiência de um retardante de longa duração, à base de polifosfato amônico, em queimas controladas em condições de laboratório. Scientia Forestalis, Piracicaba, v. 36, n. 79, p. 223-229, 2008.

CANZIAN, W. P. et al. Diferentes concentrações de retardante de fogo em plantios de eucalipto. Nativa, Sinop, v. 4, n. 4, p. 195-198, 2016.

CANZIAN, W. P. et al. Eficiência do uso da água em métodos de combate a incêndios em florestas plantadas. Nativa, Sinop, v. 6, n. 3, p. 309-312, 2018.

CAO, Y. et al. Soil microbial community composition under Eucalyptus plantations of different age in subtropical China. European Journal of Soil Biology, Montrouge, v. 46, p. 128-135, 2010.

CARMO, F. H. D. J. et al. Litter balance in areas of Eucalyptus urograndis (Clone H13) in a Cerrado-Amazon transition of Mato Grosso state, Brazil. Ciência e Natura, Santa Maria, v. 40, n. 39, p. 1-14, 2018.

DIETRICH, J. P. et al. Toxicity of PHOS-CHEK LC-95A and 259F fire retardants to ocean- and stream-type Chinook salmon and their potential to recover before seawater entry. Science of the Total Environment, Amsterdam, v. 490, p. 610-621, 2014.

ESTIARTE, M.; PEÑUELAS, J. Alteration of the phenology of leaf senescence and fall in winter deciduous species by climate change: effects on nutrient proficiency. Global Change Biology, Oxford, v. 21, n. 3, p. 1005-1017, 2014.

FIEDLER, N. C. et al. Intensidade de queima de diferentes retardantes de fogo. Revista Árvore, Viçosa, MG, v. 39, n. 4, p. 691-696, 2015.

GIMÉNEZ, A. et al. Long-term forest fire retardants: a review of quality, effectiveness, application and environmental considerations. International Journal of Wildland Fire, Rosyn, v. 13, p. 1-15, 2004.

GUILHERME, M. R. et al. Superabsorbent hydrogels based on polysaccharides for application in agriculture as soil conditioner and nutrient carrier: a review. European Polymer Journal, New 
York, v. 75, p. 365-385, 2015.

HOFFMANN, W. A. et al. Fuels or microclimate? Understanding the drivers off ire feedbacks at savana-forest boundaries. Austral Ecology, Carlton, v. 37, p. 634-643, 2012.

IBAMA. Parecer técnico, n. 514/2018-COASP/CGASQ/DIQUA, 20 de junho de 2018. Brasília: IBAMA, 2018. 15 p. Disponível em: https://www.ibama.gov.br/phocadownload/quimicose-biologicos/retardantes-de-chamas/2018-SEI_IBAMA-Parecer-Tecnico-5142018-COASPCGASQ-DIQUA.pdf. Acesso em: 18 jan. 2019.

KREYE, J. K.; KOBZIAR, L. N.; ZIPPERER, W. C. Effects of fuel load and moisture contente on fire behaviour and heating in masticated litter-dominated fuels. Internation Jounal of Wildland Fire, Rosyn, v. 22, n. 4, p. 4440-445, 2013.

LIMA, D. C. et al. Comportamento do fogo em diferentes interfaces ambientais de uma plantação de Eucalyptus urograndis. In: SEMINÁRIO DE GESTÃO DE INCÊNDIOS FLORESTAIS, 3., 2017, Cuiabá. Anais [...] Cuiabá: SGIF, 2017.

MACHADO FILHO, C. et al. Eficiência de um retardante de fogo de longa duração utilizado em incêndios florestais. Ciência Florestal, Santa Maria, v. 22, n. 2, p. 365-371, 2012.

MCCARTHY, G. J.; PLUCINSKI, M. P.; GOULD, J. S. Analysis of the resourcing and containment of multiple remote fires: the Great Divide Complex of fires, Victoria, December 2006. Australian Forestry, Queen Victoria, v. 75, p. 54-63, 2012.

NAVROSKI, M. C. et al. Influência do hidrogel no crescimento e no teor de nutrientes das mudas de Eucalyptus dunnii. Floresta, Curitiba, v. 45, n. 2, p. 315-328, 2015.

NORTH, M. P. et al. Reform forest fire management. Science, London, v. 349, n. 6254, p. 12801281, 2015.

PLUCINSKI, M. P.; SULLIVAN, A. L.; HURLEY, R. J. A methodology for comparing the relative effectiveness of suppressant enhancers designed for the direct attack of wildfires. Fire Safety Journal, Oxford, v. 87, p. 71-79, 2017.

PLUCINSKI, M. P.; PASTOR, E. Criteria and methodology for evaluanting aerial wildfire supression. International Journal of Wildland Fire, v. 22, p. 1144-1154, 2013.

RIBEIRO, G. A. et al. Eficiência de um retardante de longa duração na redução da propagação do fogo. Revista Árvore, Viçosa, MG, n. 30, n. 6, p. 1025-1031, 2006.

ROTHERMEL, R. C. A mathematical model for predicting fire spread in wildland fuels. Ogden: USDA Forest Service, 1972. 40 p.

SCHUMACHER, M. V.; WITSCHORECK, R.; CALIL, F. N. Biomassa em povoamentos de Eucalyptus spp. de pequenas propriedades rurais em Vera Cruz, RS. Ciência Florestal, Santa Maria, v. 21, n. 1, p. 17-22, 2011.

SLIJEPCEVIC, A. et al. An analysis of the effect of aspect and vegetation type on fine fuel moisture content in eucalypt forest. International Journal of Wildland Fire, Rosyn, v. 27, p. 190-202, 2018.

SOARES, R. V.; BATISTA, A. C. Incêndios florestais: controle, efeitos e uso do fogo. 1. ed. Curitiba: [s. n.], 2007. 250 p.

SOUZA, A. P. et al. Classificação climática e balanço hídrico climatológico no estado de Mato Grosso. Nativa, Sinop, n. 1, v. 1, p. 34-43, 2013.

VIERA, M. et al. Deposição de serapilheira e nutrientes em plantio de Eucalyptus urophylla x E. globulus. Floresta e Ambiente, Seropédica, v. 21, n. 3, p. 327-338, 2014. 